\title{
RELACIONAMENTO COM A MÍDIA: UMA NOVA LEITURA A PARTIR DA TEORIA DA COMPLEXIDADE ${ }^{1}$
}

\author{
MEDIA RELATIONS: A NEW READING FROM COMPLEXITY THEORY \\ RELACIONES CON LOS MEDIA: UNA NUEVA LECTURA DESDE LA \\ TEORIA DE LA COMPLEJIDAD
}

\author{
Wilson da Costa Bueno \\ Doutor, UMESP \\ e-mail:wilson@comtexto.com.br
}

\begin{abstract}
Resumo
O relacionamento entre as organizações e a mídia tem sido pensado e praticado a partir de uma perspectiva técnico-operacional que não contempla o novo cenário que redesenha a teoria e a prática da Comunicação Organizacional. $O$ artigo resgata os princípios do pensamento complexo, buscando recontextualizar a interação entre organizações, veículos e profissionais de imprensa e propõe um novo modelo para a atuação das assessorias de imprensa.
\end{abstract}

Palavras-Chave: Assessoria de imprensa. Comunicação e pensamento complexo. A relação entre empresas e mídia.

\section{Abstract}

The relationship between organizations and the media has been conceived and performed from a technical and operational perspective that does not include the new scenario for the redesign of the theory and practice of Organizational Communication. The article presents the principles of complex thinking, in order to recontextualize the interaction between organizations, vehicles and journalists and proposes a new model for the role of press offices.

Keywords: Press office. Communication and complex thought. The relationship between business and media.

\section{Resumen}

La relación entre las organizaciones y los medios de comunicación ha sido concebido y realizado desde un punto de vista técnico y operativo que no inclui el nuevo escenario que caracteriza la teoría y la práctica de la Comunicación Organizacional. El artículo presenta los principios del pensamiento complejo, recontextualizando la interacción entre las organizaciones, los vehículos y los profesionales de los medios, para proponer un nuevo modelo para el papel de las oficinas de prensa.

\footnotetext{
1 Trabalho apresentado originalmente ao Grupo de Trabalho Comunicação nos contextos organizacionais do XXII Encontro Anual da Compós, na Universidade Federal da Bahia, Salvador, de 04 a 07 de junho de 2013.
} 
Palabras-clave: Oficinas de prensa; comunicación y pensamiento complejo; relaciones entre las empresas y los medios de comunicación

\section{A desconstrução da teoria e prática tradicionais}

A literatura brasileira em Comunicação Organizacional, em particular aquela que trata especificamente do relacionamento das organizações com a imprensa, tem se caracterizado pelo conservadorismo e, com raras exceções, ainda não está repercutindo as mudanças paradigmáticas que vêm ocorrendo seja no universo da comunicação, em especial na indústria da mídia, seja nas relações das empresas com os seus públicos estratégicos e com a sociedade de maneira geral.

Por esse motivo, a maioria das obras que versam sobre este tema continua assumindo uma perspectiva meramente operacional quando analisa a interação das organizações com os veículos e jornalistas, muitas vezes se limitando a repetir fórmulas ou receitas, algumas desgastadas, para promover este relacionamento. Ela ignora processos e fenômenos emergentes que contemplam a influência crescente das mídias sociais, da comunicação focada no ambiente virtual e sobretudo não parece perceber que as organizações têm buscado reduzir a importância do papel da mídia como mediadora das suas relações com os stakeholders.

Bons textos integrais sobre relacionamento com a mídia têm sido publicados há algumas décadas e podem ser citados, entre outros, os de L.M.P. COSTA (2003), Vera DIAS (2004), Dorothy I. DOTY(1995), Maria Tereza GARCIA (2004), Elisa KOPPLIN e Luiz Arthur FERRARETTO (1993), Gerson Moreira LIMA (1985), Boanerges LOPES (1994 e 1998), Marilene LOPES ( 2000), Luciane LUCAS (2007), Maristela MAFEI (2004), Nemércio NOGUEIRA (1999), Geraldo SOBREIRA (1993), Alessandra Torrazas TAPARELLI (1999), Francisco VIANA (2001), Regina VILLELA (1998), Sérgio ZOBARAN e Leopoldo CAMARA (1994), além do trabalho considerado o mais completo sobre este tema, organizado por Jorge DUARTE (2011).

Em geral, a maioria destas obras tem como proposta apresentar informações básicas, algumas delas ilustradas com exemplos extraídos da experiência pessoal de seus autores, sobre a maneira correta de interagir com os veículos e jornalistas. Têm como objetivo evidenciar a importância do bom relacionamento com a mídia no incremento da visibilidade, da credibilidade e para consolidar a imagem/reputação das organizações. Elas envolvem subtemas importantes deste relacionamento, como a postura em momentos de crises, a 
capacitação das fontes, a obediência a atributos básicos como o profissionalismo, a ética e a transparência, a organização de coletivas de imprensa, a elaboração dos comunicados (releases) e assim por diante.

Em princípio, pode-se até reconhecer que a teoria não se afasta muito da prática e que, em certa medida, o "pensar ou pesquisar e o fazer assessoria de imprensa", continuam relegando a um segundo plano as mudanças importantes que impactam a atividade. Apesar do discurso, teoria e prática não a contemplam como um instrumento ou processo verdadeiramente estratégico para as organizações. Esse fato explica as lacunas importantes no tratamento da questão e nem sempre, muito pelo contrário, esta competência relevante do chamado "composto de comunicação" é contextualizada de modo a tornar visível a sua articulação seja com as outras competências da comunicação corporativa seja com o processo amplo de gestão das organizações.

Entre inúmeros motivos, é possível atribuir a miopia de parte significativa das estruturas de comunicação das organizações e das agências e assessorias à própria formação fragmentada, essencialmente técnica, dos profissionais que, no mercado, ocupam dessa atividade, oriundos, em sua maioria, dos cursos de Jornalismo. Embora possam conhecer razoavelmente (pelo menos aqueles que freqüentam cursos mais prestigiados) o sistema de produção jornalística, o funcionamento das redações e mesmo os perfis de determinados veículos e jornalistas, têm uma visão incompleta, imprecisa, quando não equivocada e até mesmo preconceituosa, do trabalho de relacionamento com a mídia, assim como da atividade de comunicação corporativa como um todo.

O dia-a-dia da atividade requer mais do que competência técnica porque, de há muito, o trabalho de interação com a mídia não se limita à produção de releases ou a manutenção de bons contatos nas redações, constituindo-se em um amplo e complexo processo de gestão de informações e relacionamentos, que pressupõe sobretudo a capacitação para uma leitura crítica do mercado (em suas dimensões política, econômica e sócio-cultural) e para o monitoramento/avaliação da presença e da imagem das organizações na mídia.

Conceitualmente, como de resto na maioria dos cursos de Comunicação, a proposta simplista que caracteriza o estudo e a prática em assessoria de imprensa está viesada pela fragmentação do olhar, pelo equívoco contido numa proposta pedagógica que se funda, como assinala Edgar Morin, na "inteligência cega", que "destrói os conjuntos e as totalidades, isola todos os seus objetos do seu meio ambiente" (MORIN, 2011, p.12) . 
As mudanças paradigmáticas que vêm redefinindo a relação das organizações com os seus stakeholders exigem uma nova proposta de relacionamento com a mídia e inclusive o conhecimento de que a mídia, ao contrário do que postula a literatura, assume diversas facetas. A teoria e a prática da assessoria de imprensa ainda conjugam imprensa brasileira no singular, esquecidas de que há realidades distintas em termos de produção, públicos, discursos, objetivos e intenções que caracterizam as milhares de publicações jornalísticas do país, de tal modo que seria lógico admitir que não existe uma imprensa, mas várias imprensas brasileiras.

Essa diversidade se aprofunda com o fortalecimento do espaço virtual como verdadeira incubadora de novas alternativas para o trabalho jornalístico (blogs, newsletters, portais) e, em especial, com a consolidação das redes e mídias sociais como agentes potencializadores de novos espaços de divulgação. O relacionamento com a mídia num ambiente complexo exige um repensar da atividade e o desenvolvimento de novas práticas. De imediato, é urgente contemplar a assessoria de imprensa a partir de um novo paradigma, descartando a perspectiva que a fragmenta e que a reduz a uma competência descontextualizada da gestão das organizações porque comprometida com uma circunstância eminentemente técnica e operacional.

\section{Comunicação Organizacional: uma tentativa de recontextualização}

A Comunicação Organizacional tem permanecido refém de uma perspectiva instrumentalista que não apenas contamina a sua prática, mas invade parte expressiva de sua literatura específica, marcada pela apologia de ações, estratégias e posturas que se conformam com os objetivos imediatistas do "management".

Simplifica-se a compreensão/explicação de comunicação para dar conta das necessidades de mercado, ou seja, o mercado, contrariamente ao que se pensa em uma perspectiva de complexidade, passa a ser o único elemento de definição dos processos comunicacionais. Em outros termos, o mercado procura instituir-se como determinante de toda comunicação organizacional. Nesse sentido, não são poucas as "receitas" de comunicação apresentadas por profissionais de comunicação e de marketing. (BALDISSERA, 2009,p. 157)

É forçoso, porém, reconhecer o esforço e a competência de autores brasileiros que, especialmente nos últimos anos, têm buscado disseminar os princípios básicos do pensamento complexo e propor uma releitura da teoria e da prática da Comunicação Organizacional. Destacam-se, entre eles , Rudimar BALDISSERA, Cleusa Maria Andrade 
SCROFERNECKER, Ivone de Lourdes OLIVEIRA, Maria Aparecida de PAULA, Maria SCHULER, João José CURVELLO e Cláudia Peixoto de MOURA, dentre outros.

Há várias leituras possíveis dos conceitos e análises que subsidiam a teoria da complexidade porque a trajetória dos autores que a visitam, assim como a nossa, está obrigatoriamente associada à sua formação, ao seu modo de enxergar o mundo e à ciência, em particular a Comunicação Organizacional, mas ela, fundamentalmente, está apoiada nos princípios conhecidos como o dialógico, o da recursão organizacional e o hologramático, exaustivamente difundidos na literatura que trata do tema, em particular na generosa contribuição de Edgar Morin que a eles se refere recorrentemente como pilares do pensamento complexo.

O princípio dialógico promove a conciliação entre a unidade e a diversidade, entre a ordem e a desordem, reafirmando os vínculos entre o antagonismo e a complementaridade que, no pensamento complexo, são indissociáveis.

O princípio da recursão organizacional postula o descarte da linearidade, do reducionismo simplista da relação causa/efeito, do distanciamento entre produto e produtor, entre sujeito e objeto, reafirmando que "tudo o que é produzido volta-se sobre o que o produz num ciclo ele mesmo autoconstitutivo, auto-organizador e autoprodutor" (MORIN, 2011, p.74)

Já o princípio hologramático tem a ver com a dinâmica articulação entre o todo e as partes que pode ser entendida com a contundente e incontestável conclusão: “"não apenas a parte está no todo, mas o todo está na parte" (MORIN, 2011, p.74), ou em outras palavras, ampliando esta noção básica: o todo é maior do que a soma das partes e cada parte encerra o todo.

Estes princípios dão respaldo à crítica dos estudiosos comprometidos com o pensamento complexo à teoria da simplicidade que sustenta a fragmentação dos saberes, que proclama a eficácia da hiperespecialização e que descontextualiza as relações porque privilegia uma perspectiva essencialmente estática entre sujeito e objeto, entre organizações e o seu entorno social, cultural, político e econômico. Eles buscam reverter uma lógica que, no caso da Comunicação Organizacional, abre espaço para uma proposta de planejamento (estratégico?) que se define a partir de premissas ou cenários tidos como imutáveis e para ações e posturas que buscam a todo custo manter o "status quo", comprometendo a busca ou a legitimação da diversidade, o protagonismo dos sujeitos e a auto-crítica permanente e necessária de processos de gestão reconhecimento autoritários. 
O pensamento complexo busca oxigenar a teoria e a prática da Comunicação Organizacional como reação a esta visão nitidamente mercadológica e restritiva que se funda numa lógica e numa pedagogia mesquinha porque a serviço de interesses de organizações e seus gestores que enxergam, apesar do discurso, as relações com os seus stakeholders, como do tipo "ganhar sempre e a qualquer custo". Essa postura tanto pode ser percebida pela ânsia de obter resultados quantitativamente mensuráveis (maiores vendas, maior participação no mercado, maior valor de suas ações etc) como pelo empenho em agregar valor a alguns de seus ativos intangíveis (marcas, imagem ou reputação, capacidade de inovar, compromisso com a sustentabilidade etc). Para reafirmar sua hegemonia ou liderança, sobretudo as grandes corporações que praticam uma comunicação refinada apropriam-se de um discurso hipócrita, grandiloqüente, autocrático, que não se afina com a realidade e que legitima o uso de recursos não éticos, como o abuso do poder econômico, o assédio moral, o lobby ilegítimo e as relações espúrias com o poder político.

Euclides Guimarães (2008, p.142) admite que “organizar é, por natureza, conspirar contra o acaso e tal conspiração não se faz pela afixação de hábitos, sem o qual os atos humanos se tornam sobremaneira imprevisíveis" , mas chama a atenção para o fato de que o cenário atual não permite que esse intento seja alcançado porque “ a fluidez da contemporaneidade tende a remetê-los de pronto à obsolescência".

O acirramento da concorrência pelo encurtamento das distâncias e pela transformação gradativa dos produtos em commodities, a potencialização das conversas em rede e o frenesi das mídias sociais, com a "transmutação" instantânea de posts, tweets e vídeos em pautas e notícias, reposicionam a agenda institucional das organizações, subvertendo a ordem e as hierarquias. Com isso, atenua-se o controle sobre o fluxo das informações porque a comunicação em tempo real impede que a estrutura destacada para responder às demandas informativas e às críticas se capacite, pelo menos nos moldes tradicionais, para acompanhar esse ritmo.

A gestão de processos e de pessoas sofre, portanto, alterações importantes porque precisa conformar-se a um novo cenário caracterizado pelas mudanças permanentes, pela vigilância dos stakeholders e da opinião pública de maneira geral. A nível interno, o novo perfil dos públicos (funcionários, servidores etc) pressiona as chefias em direção a uma comunicação dialógica e, embora os públicos internos não tenham conseguido ainda furar o bloqueio da blindagem autocrática das organizações e das chefias, já provocam irritações sensíveis porque suas demandas e falas criam uma formidável “zona de desconforto". Esse 
mal-estar institucional é mais acentuado porque as empresas que não estão dispostas ou capacitadas para revolucionar a sua gestão, atendendo de pronto aos novos desafios, são penalizadas pela deserção de seus talentos, em particular os que compõem a chamada geração digital, que se identificam com esse novo cenário que se desenha no horizonte.

\footnotetext{
Gerenciar se torna assim uma atividade mais de escuta que de fala, na medida em que a vigilância em nome da manutenção da ordem vai dando lugar ao monitoramento em nome do controle da desordem.Tudo isso, amalgamado pela obsessão da disputa pelo melhor resultado, tem como efeito imediato trazer para o interior da organização a lógica que antes pautava sua relação com a outra lógica, a do mercado, a concorrência. (GUIMAR ÃES, 2008, p.142-3)
}

As organizações e chefias, que durante décadas se gabaram do controle dos fluxos de informação porque se valiam da cumplicidade dos monopólios da comunicação para a divulgação de seus fatos e versões , se vêem atordoadas com a nova situação, caracterizada pelo surgimento de milhões de vozes, independentes e barulhentas, que freqüentam o Twitter e o Facebook e que dão o testemunho ao vivo nos canais de vídeo do YouTube, afrontando ruidosamente a autoridade.

A interação em tempo real das organizações com os seus stakeholders amplifica a noção de comunicação proposta por Baldissera (2004) - "processo de construção e disputa de sentidos" (p.128) - porque remete o embate para a arena virtual, espaço em que as empresas não se sentem confortáveis, seja porque não estão acostumadas a digladiar fora do seu território (elas levam vantagens quando competem dentro de casa porque conhecem as circunstâncias do terreno em que pisam), seja porque no ambiente virtual nem sempre elas podem escolher as armas ou fixar unilateralmente as regras do jogo.

Nesse sentido, as organizações precisam lidar com uma visão moderna de estratégia e com uma nova maneira de contemplar os seus stakeholders. Sai de cena o "público-alvo" e surge vigoroso o "público de interesse" e essa distinção não reside apenas em um jogo de palavras, mas em uma reformulação profunda de conceitos. Ao público-alvo as empresas costumavam endereçar as suas ações de marketing, conformando-o ao seu processo de produção e ao seu discurso. O público de interesse interage, reivindica, questiona, problematiza e não permanece refém do discurso e das posturas das organizações.

A noção de estratégia, verdadeiramente inserida no contexto do pensamento complexo, não se identifica com a perspectiva essencialmente analítica, lógico-determinista, racionalista que predomina na teoria (ou teorias) das organizações em que se postula a imperiosa necessidade do planejamento (estratégico, é claro). Numa sociedade multifacetada, em que fervilham os interlocutores, que se consolidam também como protagonistas, e 
prevalecem as interações recursivas, as estratégias não podem ficar restritas a processos relacionais que não incorporam o pluralismo, típicas de uma mentalidade organizacional “transgênica” que, segundo expressão felicíssima de Vandana Shiva (2003), legitima as "monoculturas da mente".

As estratégias, afinadas com a contemporaneidade, precisam assumir um novo perfil porque só farão sentido se incorporarem os atributos básicos de uma economia e de uma sociedade colaborativas, multimidiáticas, multirelacional e que, conforme explicam Maria do Carmo Reis e Marlene Marchiori (2010), devem ser pensadas não como percursos previsíveis e passíveis de controle.

\footnotetext{
...as estratégias ganham novo significado: deixam de ser compreendidas como caminhos seguros - planejados e controlados - de condução ao desejável pela alta administração e se transformam em perspectivas de longo alcance que, apesar de propostas pela alta administração, são, segundo Jarzabkowski, Balogun e Seidl (2007), efetivamente construídas por meio da contribuição de vários agentes (internos, externos, hierarquicamente diferenciados).
}

A gestão das relações com os stakeholders, a exemplo da recontextualização que buscamos fazer entre comunicação e estratégia, não pode ser trabalhada a partir do modelo mental que governa a teoria da simplicidade e que a enxerga sob a mesma ótica racionalista, analítica e unidirecional. Ela precisa considerar que as organizações e os seus públicos estratégicos, como prevê o princípio da recursão organizacional, interagem dinâmicamente e que negociam o tempo todo, buscando restabelecer um equilíbrio que favoreça a consecução não apenas de seus objetivos e interesses, mas de toda a sociedade. Essa relação é estabelecida, portanto não apenas pelas partes diretamente envolvidas nessa interação (organizações e stakeholders), mas sofre a interferência do mercado, da cultura, do tempo histórico que provê condições concretas e específicas, a cada momento, de acesso a tecnologias e pode ser mediada pela imprensa, esta também refém dos mesmos fatores condicionantes.

\section{Assessoria de imprensa e complexidade}

As observações feitas anteriormente remetem para uma nova proposta de relacionamento com a mídia que leve em conta esse cenário complexo e especialmente sinalizam para a necessidade de rever a teoria e a prática que subsidiam o modelo tradicional de relacionamento com a imprensa, buscando superar os limites da mera competência técnica. 
Para isso, estaremos assumindo a necessidade de recontextualizar conceitos básicos, como o de estratégia, e de avaliar alguns recursos utilizados para instrumentalizar essa relação, como as salas de imprensa virtuais, os comunicados de imprensa (releases) e o sistema de informações que subsidia o trabalho das assessorias de imprensa (cadastro de jornalistas e de veículos).

O relacionamento com a imprensa tem sido entendido como indispensável para criar e consolidar a imagem e a reputação das organizações e para agregar valor aos negócios e está respaldado na convicção de que os veículos (empresários e editores) e os jornalistas de maneira geral se constituem em públicos estratégicos e que merecem por isso especial atenção das organizações.

A literatura que trata desta atividade ou competência é pródiga em fórmulas (receitas, dicas e conselhos) para estabelecer procedimentos adequados de interação com os profissionais de imprensa, mas, quase sempre, respaldada numa prática já secular, legitima uma lógica ultrapassada porque comprometida com uma visão linear, reducionista da relação entre organizações e stakeholders. Na verdade, o contexto em que se inserem as organizações (globalização, explosão das redes e mídias sociais, concorrência às vezes predatória, politização das relações comerciais, supervalorização dos ativos intangíveis etc) e a própria imprensa (consolidação das alternativas digitais de divulgação de informações, segmentação exacerbada, fragmentação das instâncias de produção etc) se modificou drasticamente nas duas últimas décadas e as estratégias de interação entre os dois lados não são mais adequadas ou suficientes.

Essa alteração define uma nova lógica de relacionamento mesmo porque há um fato indiscutível: a imprensa tem perdido substancialmente peso e importância como mediadora das relações entre as organizações e os demais stakeholders. A comunicação virtual tem permitido que as empresas potencializem canais alternativos para a interação com os seus públicos de interesse (portais e sites, blogs e microblogs, redes e mídias sociais como Twiter, Facebook e YouTube, dentre outras) e, desta forma, a imprensa não se constitui mais nem na única e nem na mais eficiente instância de mediação. Isso não significa que ela ainda não desempenhe papel relevante (a credibilidade da mídia ainda qualifica as informações que veicula a respeito das organizações), mas é lícito aceitar que cada vez menos as organizações dependem dela para acessar os seus stakeholders, municiando-os com os fatos e versões de seu interesse. 
Além disso, é imperioso destacar que os meios de comunicação não são, como muitas vezes a literatura e os gestores de comunicação parecem indicar, de forma exclusiva ou majoritariamente, responsáveis pela formação da opinião pública, cujo conceito também tem merecido revisões sucessivas, sobretudo para ressaltar a sua transitoriedade ou fluidez. Ainda mais: não é necessariamente a imprensa, ou pelo menos só a imprensa, que molda a percepção que os stakeholders fazem das organizações, cristalizando-a na chamada imagem ou reputação empresarial.

As modernas teorias da comunicação têm sistematicamente chamado a atenção para a importância dos gatekeepers e mesmo para a existência de líderes informais, interna ou externamente às organizações, que re(interpretam) os fatos e versões veiculados pela mídia. As redes e mídias sociais têm contribuído decisivamente para empoderar novos protagonistas no universo da informação, como os blogueiros influentes e especializados em determinados temas e questões, muitos deles jornalistas que mantêm espaço autônomo em relação às redações.

Esse fato é tão óbvio, na moderna sociedade da informação, que renomados estudiosos e consultores têm dedicado atenção especial ao seu papel, seja porque os blogueiros estão capacitados para interagir com os stakeholders (e influenciá-los), seja porque têm sido acessados como fontes relevantes para as reportagens elaboradas pelas redações tradicionais.

David Meerman Scott (2011 e 2008), tido como um estrategista bem sucedido da comunicação on line, sugere repetidamente que as organizações busquem estabelecer parcerias com os blogs, reconhecendo-os como espaços influentes no processo de circulação de informações.

Ana Luísa de Castro Almeida e Janete Lara de Oliveira Bertucci, citando Clarkson (1995), consideram a mídia como stakeholders secundários - “aqueles influenciam ou afetam a organização e também são influenciados por ela, mas que não estão diretamente engajados em transações com a empresa e não são essenciais para a sua sobrevivência (2010, P.194). Valendo-se da contribuição de Mitchell, Agle e Wood (1997), que se respaldam nos atributos de poder, urgência e legitimidade para categorizar os diferentes stakeholders de uma organização, as autoras chegam a sugerir que a imprensa reúne com mais intensidade os atributos de urgência e legitimidade (nesta ordem) que de poder, embora admitam que, em determinados momentos ou contextos, ela pode incorporar (esse raciocínio se aplica a todos os stakeholders) o elemento que lhe falta. Embora essa avaliação da imprensa possa merecer reparos, sobretudo numa sociedade como a brasileira em que as relações entre a mídia, o 
poder político e econômico são tão estreitas (a maioria dos veículos e emissoras é de propriedade ou sofre forte influência de empresários e parlamentares), podemos admitir que pelo menos o poder da imprensa tem sido gradativamente atenuado. Nem sempre campanhas agressivas encetadas pela mídia têm redundado no apoio incondicional da opinião pública e muitas teses ou causas assumidas pela imprensa não têm merecido a adesão da sociedade.

A teoria e a prática da assessoria de imprensa, desconsiderando os cânones do pensamento complexo, costumam considerá-la desconectada do composto de comunicação e, apesar do discurso recorrente da chamada "comunicação integrada", na maioria das organizações, elas ainda se reduzem à divulgação unilateral de informações com o objetivo de sensibilizar a mídia. Não é incomum inclusive encontrarmos, no mercado profissional e na bibliografia que contemplam essa atividade, embates formidáveis entre duas importantes competências comunicacionais (e as categorias profissionais que as representam) Jornalismo e Relações Públicas, tendo em vista a gestão desse processo de interação com a mídia.

A segmentação da mídia, com o crescimento exponencial de veículos e editorias especializadas, tem dificultado a percepção do ethos da imprensa e descontextualiza a sua relação com o poder político e econômico, o que se constitui, de pronto, em obstáculo à implementação de uma análise ou avaliação respaldadas no pensamento complexo.

A apologia da hiperespecialização da imprensa no trato de temas ou assuntos (proclama-se a irreversibilidade da especialização jornalística) encontra eco e suporte na real divisão do sistema de produção jornalística, distribuído em editorias, que não apenas segmenta a cobertura mas fragmenta o olhar. Essa postura reproduz, em larga medida, o processo secular de fragmentação do saber que culminou com sua divisão em disciplinas, promovendo o estilhaçamento do conhecimento, a separação entre ciência e filosofia e o primado do formalismo e da matematização. A objetividade, uma noção equivocada mas que ainda vigora em boa parte da literatura e da prática jornalísticas, também respaldou a chamada epistemologia da simplificação a que se refere Edgar Morin, culminando na partição dos conhecimento e na constituição de territórios ou disciplinas que se pretendem autosuficientes.

As editorias e os veículos segmentados devem ser considerados no trabalho de relacionamento com a mídia porque se constituem em entidades reais, mas não podem ser vistos isoladamente porque constituem partes de um todo e, como ensina a teoria da complexidade, elas o encerram e, no conjunto, o superam. 
O trabalho de relacionamento com a imprensa precisa resgatar o todo (os veículos como entidades unas e múltiplas em mutação) porque é ele que justifica a sua linha editorial, seus vínculos e compromissos, mas ao mesmo tempo considerar a autonomia das partes porque, no sistema de divisão de trabalho, pressionado pela urgência do tempo, elas muitas vezes operacionalizam posições e posturas próprias. É mais comum do que se pode imaginar o tensionamento das relações entre jornalistas (e as editorias que os agrupam) com as chefias diretas (editores) e com os proprietários da mídia. Veículos e emissoras têm frequentemente enfrentado crises por divergência de opiniões e em virtude de embates naturais na relação capital x trabalho.

As assessorias de imprensa nem sempre conseguem identificar essas tensões que, se percebidas, poderiam permitir o aproveitamento de brechas que existem pela relativa autonomia de espaços de produção (editorias) e mesmo de jornalistas, particularmente aqueles que desfrutam de maior prestígio. Articulistas e colunistas, em função do seu prestígio junto à audiência (leitores, radiouvintes, espectadores etc) muitas vezes expressam em seus espaços exclusivos (artigos ou colunas) opiniões e pontos de vista que conflitam com os de seus veículos e essa divergência é negociada e aceita como saudável para a convivência e para os negócios.

A prática da assessoria de imprensa também se respalda em instrumentos ou recursos que, mantida a sua proposta tradicional, estão cada vez mais deslocados do processo moderno de interação entre jornalistas e organizações. É o caso dos releases que ainda mantêm seu tom nitidamente persuasivo, comprometidos com um processo cada vez menos eficaz de convencimento dos profissionais de imprensa sobre as qualidades das organizações e de seus produtos e serviços. Os comunicados de imprensa continuam privilegiando a mera transmissão de informações de interesse da organização, num esforço repetitivo e enjoado que não está sintonizado com uma proposta efetiva de diálogo, de parceria e, embora existam agências e assessorias que o enxergam de maneira menos instrumental e o utilizam colaborativamente, elas se constituem em exceção.

As facilidades potencializadas pela comunicação virtual multiplicaram de forma espantosa a distribuição de releases, de tal modo que as redações (e os jornalistas em particular) têm tido dificuldade para acessá-los em sua rotina estafante de trabalho. As assessorias não têm se dado conta de que as tecnologias que oportunizam o encaminhamento de comunicados de imprensa permitem, em contrapartida que eles sejam filtrados, o que acontece invariavelmente com a maioria deles, em especial quando, por experiências 
anteriores, os jornalistas conseguem identificar a sua origem e associá-la a fornecedores de informações jornalisticamente não relevantes.

Da mesma forma, as Salas de imprensa (espaços virtuais privativos para a interação entre organizações e jornalistas), cada vez mais comuns nos portais das empresas, mantêm essa visão simplista, estão comprometidas com a disponibilização de dados e informações e não com uma proposta de colaboração com o trabalho da mídia. Não passam, com raras e honrosas exceções, de depósitos de releases, fotos, notícias, vídeos de campanhas publicitárias e clipping de imprensa que, segundo os que as planejam, poderão ser acessados pelos jornalistas e render espaço nos veículos. Dificilmente estão estruturadas para atender, com agilidade e precisão, as demandas dos profissionais de imprensa e se limitam a espaços virtuais estáticos, que não levam em conta a dinâmica da produção jornalística e não estão capacitadas para promover a qualificação da cobertura.

Os bancos de dados que suportam o trabalho de relacionamento com a mídia costumam ser incompletos ou imprecisos porque, na prática, limitam-se a meros cadastros que se respaldam em poucos atributos básicos (cargo e editoria a quem pertencem os jornalistas, além evidentemente do seu nome e formas de acesso - e-mail, endereço da redação etc). Não incorporam , por exemplo, a visão desses profissionais em relação a temas estratégicos para as organizações, o que permitiria, de forma inteligente, ações ou formas específicas de interação (conversas, envio e troca de materiais etc) visando neutralizar ou atenuar posições adversas ou invocar a sua parceria para assuntos de interesse. Não trazem informações sobre a sua trajetória (vínculo a partidos políticos ou entidades, inclusive Igrejas ) sobre a sua manifestação em relação à organização ou a setor (ou setores) em que ela atua ou mesmo sobre seu vínculo com questões fundamentais, como a sustentabilidade, a relação das organizações com o governo e assim por diante.

A assessoria de imprensa moderna precisa, portanto, se constituir em um sistema, processo ou instrumento de inteligência que compatibilize a operacionalização do processo de produção jornalística, cada vez mais especializado, com o conhecimento adequado dos vínculos e compromissos de veículos e emissoras. Precisa considerar o todo e as partes em uma articulação dinâmica e extrapolar a instância meramente técnica, consubstanciada na produção e emissão de releases, para redimensionar o trabalho de relacionamento com a mídia como uma atividade que se processa em um contexto informativo, mas também econômico, político e sócio-cultural. Ela deve assumir como natural a tensão entre organizações e mídia, cujos interesses e objetivos nem sempre se confundem, assim como as disputas internas nas 
estruturas de produção da mídia, que definem embates mediados pela urgência do tempo , pelas trajetórias e experiências de vida, pelas diferentes visões de mundo e posições sobre temas específicos, o que inevitavelmente confere autonomia relativa aos jornalistas. Sobretudo, ela deve assumir que se materializa em um ambiente complexo, em constante mudança, que se respalda, muitas vezes (ou quase sempre) em fontes e fatos, respectivamente, não aceitos como únicos ou verdadeiros.

Enxergar o relacionamento com a mídia a partir de um novo modelo é fundamental para as organizações e, até prova em contrário, o pensamento complexo está mais capacitado do que a visão simplista para entender e interpretar os novos ambientes e desafios.

\section{REFERÊNCIAS}

ALMEIDA, Ana Luísa de Castro; BERTUCCI, Janete Lara de Oliveira. Gestão estratégica de stakeholders: aspectos relevantes na definição de políticas de relacionamento. In:

MARCHIORI, Marlene (org). Comunicação e organização: reflexões, processos e práticas. São Caetano do Sul: Difusão Editora, 2010, p. 191-207.

ARGENTI, Paul A; BARNES, Courtney M. Sobrevivendo na selva da internet: como fazer uma comunicação poderosa na web e protegera a reputação de sua empresa. São Paulo: Editora Gente, 2011.

BALDISSERA, Rudimar. A teoria da complexidade e novas perspectivas para os estudos de comunicação organizacional. In: KUNSCH, Margarida Maria Krohling (org). Comunicação Organizacional: histórico, fundamentos e processos. Vol. 1. São Paulo: Saraiva, 2009, p. $135-64$.

BALDISSERA, Rudimar. Organizações como complexos de diálogos, subjetividades e significação. In: KUNSCH, Margarida Maria Krohling (org). A comunicação como fator de humanização das organizações. São Caetano do Sul: Difusão Editora, 2010, p. 61-76.

BALDISSERA, Rudimar. Comunicação Organizacional: uma reflexão possível a partir do paradigma da complexidade. In: OLIVEIRA, Ivone de Lourdes; SOARES, Ana Thereza Nogueira (org). Interfaces e tendências da comunicação no contexto das organizações. São Caetano do Sul: Difusão Editora, 2008, p. 149-77.

BUENO, Wilson da Costa. Comunicação Empresarial: políticas e estratégias. São Paulo: Saraiva, 2009.

CLARKSON, M.B.E. A stakeholder framework for analyzing and evaluating corporate social performance. Academy of Management Review. v.20, p.92-117, jan.1995.

COSTA, L.M.P. (org). O X da questão: jornalistas de redação e de assessoria de imprensa. Taubaté/SP: Papel Brasil, 2003. 
DIAS, Vera. Como virar notícia e não se arrepender no dia seguinte. Rio de Janeiro: Objetiva, 1994.

DOTY, Dorothy I. Divulgação jornalística \& relações públicas. São Paulo: Cultura Editores Associados, 1995.

DUARTE, Jorge (org). Assessoria de imprensa e relacionamento com mídia. $4^{\mathrm{a}}$ ed. São Paulo:Atlas, 2011.

DUARTE, Jorge; CARVALHO, Nino. Sala de imprensa on line. In: DUARTE, Jorge (org). Assessoria de imprensa e relacionamento com mídia. $4^{a}$ ed. São Paulo:Atlas, 2011, p. 370386.

FARIAS, Luiz Alberto de. Estratégias de relacionamento com a mídia. In: KUNSCH, Margarida Maria Krohling (org). Gestão estratégica em Comunicação Organizacional e Relações Públicas. São Caetano do Sul: Difusão Editora, 2008, p. 91-104.

GARCIA, Maria Tereza. A arte de se relacionar com a imprensa. São Paulo: Novatec, 2004.

GUIMARÃES, Euclides. Notas sobre a complexidade nas organizações e nas ciências sociais. In: OLIVEIRA, Ivone de Lourdes; SOARES, Ana Thereza Nogueira (org). Interfaces e tendências da comunicação no contexto das organizações. São Caetano do Sul: Difusão Editora, 2008, p. 131-148.

KOPPLIN, Elisa; FERRARETTO, Luiz Artur. Assessoria de imprensa: teoria e prática. Porto Alegre: Sagra, 1993.

KUNSCH, Margarida Maria Krohling (org). A comunicação como fator de humanização das organizações. São Caetano do Sul: Difusão Editora, 2010.

KUNSCH, Margarida Maria Krohling (org). Comunicação Organizacional: histórico, fundamentos e processos. Vol. 1. São Paulo: Saraiva, 2009.

KUNSCH, Margarida Maria Krohling (org). Gestão estratégica em Comunicação Organizacional e Relações Públicas. São Caetano do Sul: Difusão Editora, 2008.

KUNSCH, Margarida Maria Krohling (org). Relações Públicas e Comunicação Organizacional: campos acadêmicos e aplicados de múltiplas perspectivas. São Caetano do Sul: Difusão Editora, 2009.

LIMA, Gerson Moreira. Releasemania. São Paulo: Summus, 1985.

LOPES, Boanerges; VIEIRA, Roberto Fonseca. Jornalismo e Relações Públicas: ação e reação. Uma perspectiva conciliatória possível. Rio de Janeiro: Mauad, 2004.

LOPES, Boanerges. Abaixo o nada a declarar! $O$ assessor de imprensa na era da globalização. Rio de Janeiro:Zabelê, 1998. 
LOPES, Boanerges. O que é assessoria de imprensa. São Paulo: Brasiliense, 1994.

LOPES, Marilene. Quem tem medo de ser notícia? São Paulo: Makron Books, 2000.

LUCAS, Luciane (org). Media training: como agregar valor ao negócio melhorando a relação com a imprensa. São Paulo: Summus, 2007.

MAFEI, Maristela. Assessoria de imprensa: como se relacionar com a mídia. São Paulo: Contexto, 2004.

MARCHIORI, Marlene (org). Comunicação e organização: reflexões, processos e práticas. São Caetano do Sul: Difusão Editora, 2010.

MITCHEL, R.K;AGLE, B.R.; WOOD, D. J. Toward a theory of stakeholder identification and salience: defining the principle of who e what really counts. Academy of Management Review. V.22, n.4, p.853-886, oct. 1997.

MORIN, Edgar. Introdução ao pensamento complexo. $4^{\mathrm{a}}$ ed. Porto Alegre:Sulina, 2011.

MOURA, Cláudia Peixoto de. Práticas acadêmicas em Relações Públicas: processos, pesquisas, aplicações. Porto Alegre: Sulina, 2011.

NOGUEIRA, Nemércio. Media training. São Paulo: Cultura Editores Associados, 1999.

OLIVA, Ana Paula de Oliveira. Universidade on line: as Salas de Imprensa em universidades paulistas. Dissertação (Mestrado) - Programa de Pós-Graduação em Comunicação Social da Umesp, São Paulo, 2008.

OLIVEIRA, Ivone de Lourdes; SOARES, Ana Thereza Nogueira (org). Interfaces e tendências da comunicação no contexto das organizações. São Caetano do Sul: Difusão Editora, 2008.

REIS, Maria do Carmo;MARCHIORI, Marlene. A relação comunicação-estratégia no contexto das práticas organizacionais. In: MARCHIORI, Marlene (org). Comunicação e organização: reflexões, processos e práticas. São Caetano do Sul: Difusão Editora, 2010, p.167-87.

SCHULER, Maria. Comunicação e transdisciplinaridade na era da complexidade. In: KUNSCH, Margarida Maria Krohling (org). Relações Públicas e Comunicação Organizacional: campos acadêmicos e aplicados de múltiplas perspectivas. São Caetano do Sul: Difusão Editora, 2009, p. 183- 202.

SHIVA, Vandana. Monoculturas da mente. São Paulo:Editora Gaia, 2003.

SCOTT, David Meerman. As novas regras do marketing e de Relações Públicas. Rio de Janeiro: Elsevier, 2008.

SCOTT, David Meerman. Marketing e comunicação em tempo real. São Paulo:Évora, 2011. 
SCROFERNEKER, Cleusa Maria Andrade (org). O diálogo possível: Comunicação Organizacional e paradigma da complexidade. Porto Alegre: EDIPUCRS, 2008.

SCROFERNEKER, Cleusa Maria Andrade. Comuncação Organizacional: certezas e incertezas. In: SCROFERNEKER, Cleusa Maria Andrade (org). O diálogo possível: Comunicação Organizacional e paradigma da complexidade. Porto Alegre: EDIPUCRS, 2008, p.15-30.

SOBREIRA, Geraldo. Como lidar com os jornalistas. São Paulo: Geração Editorial, 1993.

TAPARELLI, Alessandra Torrazas et al. Relações assessorias \& redações. São Paulo: Sindicato dos Jornalistas Profissionais no Estado de São Paulo, 1999.

VIANA, Francisco. De cara com a mídia: comunicação corporativa, relacionamento e cidadania. São Paulo: Negócio, 2001.

VILLELA, Regina. Quem tem medo da imprensa? Rio de Janeiro: Campus, 1998.

ZOBARAN, Sérgio; CAMARA, Leopoldo. A segunda imprensa. Rio de Janeiro: Rocco, 1994.

Artigo recebido em: 09/07/2013

Aceito para publicação em: 31/07/2014

Sobre o autor

Wilson da Costa Bueno

Professor do Programa de pós-graduação em Comunicação Social da UMES, jornalista, tem mestrado e doutorado em Comunicação pela

USP. Editor de sites temáticos em

Comunicação/Jornalismo. 